\title{
Warm Season Temperature-Mortality Relationships in Chisinau (Moldova)
}

\author{
Roman Corobov, ${ }^{1}$ Scott Sheridan, ${ }^{2}$ Kristie Ebi, ${ }^{3}$ and Nicolae Opopol ${ }^{4}$ \\ ${ }^{1}$ Eco-TIRAS International Environmental Association, 9/1 Independentii Street, Apartment. 133, 2060 Chisinau, Moldova \\ ${ }^{2}$ Department of Geography, Kent State University, Kent, OH 44242, USA \\ ${ }^{3}$ Department of Global Ecology, Carnegie Institution for Science, Stanford, CA 94305, USA \\ ${ }^{4}$ Hygiene and Epidemiology Department, State Medical and Pharmaceutical University, 67a Gh. Asachi Street, 2028 Chisinau, Moldova
}

Correspondence should be addressed to Roman Corobov; rcorobov@gmail.com

Received 22 August 2012; Accepted 19 November 2012

Academic Editor: Sunling Gong

Copyright (C) 2013 Roman Corobov et al. This is an open access article distributed under the Creative Commons Attribution License, which permits unrestricted use, distribution, and reproduction in any medium, provided the original work is properly cited.

Results of the epidemiological study of relationships between air temperature and daily mortality in Chisinau (Moldova) are presented. The research's main task included description of mortality dependence on different temperature variables and identification of thermal optimum (minimal mortality temperature, MMT). Total daily deaths were used to characterize the mortality of urban and rural populations in April-September of 2000-2008, excluding the extremely warm season of 2007. The simple moving average procedure and 2nd-order polynomials were used for daily mean $\left(T_{\text {mean }}\right)$, maximum $\left(T_{\max }\right)$, and minimum $\left(T_{\min }\right)$ temperatures and mortality approximation. Thermal optimum for mortality in Chisinau (15.2 deaths) was observed at $T_{\text {mean }}$, $T_{\max }$, and $T_{\min }$ about $22^{\circ} \mathrm{C}, 27-28^{\circ} \mathrm{C}$, and $17-18^{\circ} \mathrm{C}$, respectively. Considering these values as certain cut-points, the correlations between temperature and mortality were estimated below and above MMTs. With air temperatures below its optimal value, each additional $1^{\circ} \mathrm{C}$ increase of $T_{\text {mean }}\left(T_{\max }, T_{\min }\right)$ was accompanied by $1.40 \%(1.35 \%, 1.52 \%)$ decrease in daily mortality. The increase of $T_{\text {mean }}$ and $T_{\max }$ above optimal values was associated with $\sim 2.8 \%$ and 3.5\% increase of mortality; results for $T_{\min }$ were not statistically significant. The dependency of mortality on apparent temperature was somewhat weaker below MMT; a significant relationship above MMT was not identified.

\section{Introduction}

Mortality rates are ambient temperature dependent and have long been associated with the effects of both heat and cold. Research by epidemiologists and climatologists has grown rapidly following the European heat waves in 2003 [1-11]. That summer many western European countries experienced dramatic death tolls, and temperatures were considered as "a shape of things to come" [12].

However, while an analysis of isolated heat waves provides a useful insight into the short-term response of populations to these events, the time-series epidemiological analysis of temperature-mortality association over a long time period enables the investigation and quantification of not only general temperature-related mortality dependencies, but also additional meteorological, environmental and social confounding risk factors (e.g., [1, 13-16]). In such studies, a J- or $\mathrm{U}$-shaped relationship between temperature and mortality is often identified $[4,6]$.

Air temperature is usually expressed in terms of its mean $\left(T_{\text {mean }}\right)$, maximum $\left(T_{\max }\right)$, or minimum $\left(T_{\min }\right)$ values as well as the composite indices such as apparent temperature (AT) that takes into account humidity; in particular, it was shown that heat-related mortality is generally better identified when effects of high humidity are taken into account [17]. A greater response of mortality to daily $T_{\max }$ was shown by Kyselý and Krŕí̌ [18] and Michelozzi et al. [19]; Gosling et al. [4] noted that very little attention is paid to the explicit role of a diurnal temperature range. 
TABLE 1: Mean air temperature and aggregated daily deaths in AprilSeptember in Chisinau.

Years

200020012002200320042005200620072008

\begin{tabular}{llllllllll}
\hline $\begin{array}{l}\text { Air } \\
\text { temperature }\end{array}$ & 18.5 & 18.1 & 18.5 & 18.4 & 17.3 & 18.2 & 18.0 & 19.9 & 18.2 \\
$\begin{array}{l}\text { Mortality } \\
\text { counts }\end{array}$ & 2802 & 2748 & 2966 & 2939 & 2880 & 3115 & 2978 & 3108 & 3117 \\
\hline
\end{tabular}

This paper presents a part of the comprehensive analysis of impacts on human health carried out in the framework of climatological and epidemiological justification of the development of Heat Health Warning System (HHWS) for Moldova. The research was motivated by observations of a general warming of Moldova's climate, including the record heat waves of 2007 [20], and a complete lack of national biometeorological research in the country in recent times, especially concerning the impact of elevated summer temperatures. Therefore, the main goal of this paper was to present the first modern study of the regional relationships between population mortality and a warm period temperature regime in the capital city of Chisinau.

\section{Materials and Methods}

2.1. Initial Data. The air temperature exposure was examined during the warm seasons (April 1 to September 30) over the nine-year study period (2000-2008).

Daily mortality data comprised total daily counts of deaths from all causes in the resident population of Chisinau. This information was retrieved from the death certificates archived at the National Center of Management in Health. The data represented both urban and rural population. As of 1 January 2009, of the 785,400 residents of Chisinau, 716,920 $(91.3 \%)$ resided in the city itself, with the remainder in the suburban area. On the whole, the study encompassed about a quarter of Moldova's population at that time, including about half of the urban one.

Daily meteorological data were provided by the State Hydrometeorological Service. The daily values were calculated as the average of eight $3 \mathrm{~h}$ measurements. The chosen period is long enough for statistical processing and does not include a significant long-term trend in air temperature (Table 1). Since the goal of research was to find the shape of relationships between ambient temperature and mortality for "typical" years, the year 2007, when the extremely intensive heat waves were recorded, was excluded.

In addition, apparent temperature (AT), as a measure of perceived exposure, was derived according to Steadman [21]:

$$
\mathrm{AT}=-2.653+\left(0.994 * T_{a}\right)+\left(0.0153 * T_{d}^{2}\right),
$$

where $T_{a}$ is air temperature and $T_{d}$ is dew point temperature. Because apparent temperature was one of the main exposure measures, humidity was not modeled separately.
2.2. Temperature-Mortality Relationships Identification. This research involves explaining mortality as a health outcome based upon ambient air temperature, considered as a predictor, and potentially confounding variables, for example, month (season). To identify temperature-mortality relationships, both dependent (death) and independent (daily temperature) variables were averaged over the entire sample period: 2000-2008 years without the year 2007 (hereafter, for the sake of simplicity, in all descriptions of this period it is implied that 2007 is omitted). Such averaging smoothed the possible long-term trends and year-to-year variability in data and improved "signal-to-noise" ratio.

Because mortality has its inherent seasonal cycle that is not directly related to immediate atmospheric conditions, some forms of smoothing are usually used to account for seasonal patterns $[2,13,22,23]$. In our study, a simple moving average procedure was used to choose the optimal degree of smoothing. To identify the statistically significant differences among monthly averaged deaths, or the presence of seasonality in daily mortality, the one-way analysis of variance (ANOVA) statistical tool [24] was applied.

The different forms of regression analysis, which utilized temperature variables as independent variables and mortality as a dependent variable, serve as a reliable research tool for the adequate description of temperature-mortality relationships. Given that the temperature-mortality relationship tends to be $\mathrm{U}$-shaped, and the left and right slopes of the U-like curve represent respectively the cold- and heat-related impacts of temperature, these two segments of impacts need to be accounted for separately $[13,25,26]$.

To calculate these slopes separately, it is important to find the breakpoint where, while temperature increases, mortality no longer decreases, thus reaching its minimum value, and increases thereafter. This thermal optimum [8] corresponds to the average temperature with the lowest mean mortality. Some research, for example, Vigotti et al. [26], uses for this point the term "minimum mortality temperature" (MMT). As far back as in the 1990s, the Europe-wide Euro summer project [27] revealed the existence of a relatively narrow temperature band in which mortality is the lowest. This band varies substantially within Europe, the USA and other countries (e.g., [28]). Different methods are used to identify MMT. For instance, Donaldson et al. [28] calculated the temperature at which daily mortality was the lowest by computing the mean daily mortality over a range of $3^{\circ} \mathrm{C}$ at successive $0.1^{\circ} \mathrm{C}$ intervals. The upper margin of this band was taken as the temperature of heat-related mortality onset. They also found that using narrower bands gives data with excessive random variability. The same approach was used by Laaidi et al. [8] to study temperature-related mortality in France. To smooth the high variability in daily mortality, sometimes evident at higher temperatures, the $2^{\circ} \mathrm{C}$ class interval was used by Gosling et al. [6].

In our research, the narrow-band approach has proved itself to be a good identifier of thermal optima as well as excess death thresholds in the heat-event study [29]. We grouped daily deaths into $2^{\circ} \mathrm{C}$ temperature class intervals with $0.01^{\circ} \mathrm{C}$ increments; such increments allow preserving all 
TABLE 2: Descriptive statistic of monthly averages of total daily mortality in Chisinau, 2000-2008.

\begin{tabular}{|c|c|c|c|c|c|c|c|c|c|c|}
\hline \multirow{2}{*}{ Month } & \multirow{2}{*}{$T_{\text {mean }}{ }^{\circ} \mathrm{C}$} & \multicolumn{9}{|c|}{ Death counts } \\
\hline & & Sum & Average & $\mathrm{Sd}$ & $\mathrm{CV}, \%$ & Min & Max & Range & Ssk & Sku \\
\hline April & 10.8 & 536 & $17.9 \pm 0.28$ & 1.69 & 9.4 & 14.5 & 20.5 & 6.0 & -0.08 & -1.11 \\
\hline May & 16.8 & 517 & $16.7 \pm 0.27$ & 1.76 & 10.5 & 13.1 & 20.5 & 7.4 & -0.09 & -0.43 \\
\hline June & 19.8 & 480 & $16.0 \pm 0.28$ & 1.64 & 10.2 & 12.8 & 18.8 & 6.0 & -0.95 & -0.60 \\
\hline July & 22.6 & 462 & $14.9 \pm 0.27$ & 1.15 & 7.7 & 11.6 & 16.5 & 4.9 & -1.71 & 0.63 \\
\hline August & 22.4 & 475 & $15.3 \pm 0.27$ & 1.40 & 9.2 & 12.2 & 18.2 & 6.0 & -0.66 & -0.71 \\
\hline September & 16.2 & 475 & $15.8 \pm 0.28$ & 1.44 & 9.1 & 13.1 & 19.4 & 6.3 & 1.10 & 0.23 \\
\hline Period & 16.1 & 2946 & $16.1 \pm 0.26$ & 1.79 & 11.1 & 11.6 & 20.5 & 8.9 & 1.53 & -0.35 \\
\hline
\end{tabular}

Sd: standard deviation; CV: coefficient of variation; Ssk: standardized skewness; Sku: standardized kurtosis.
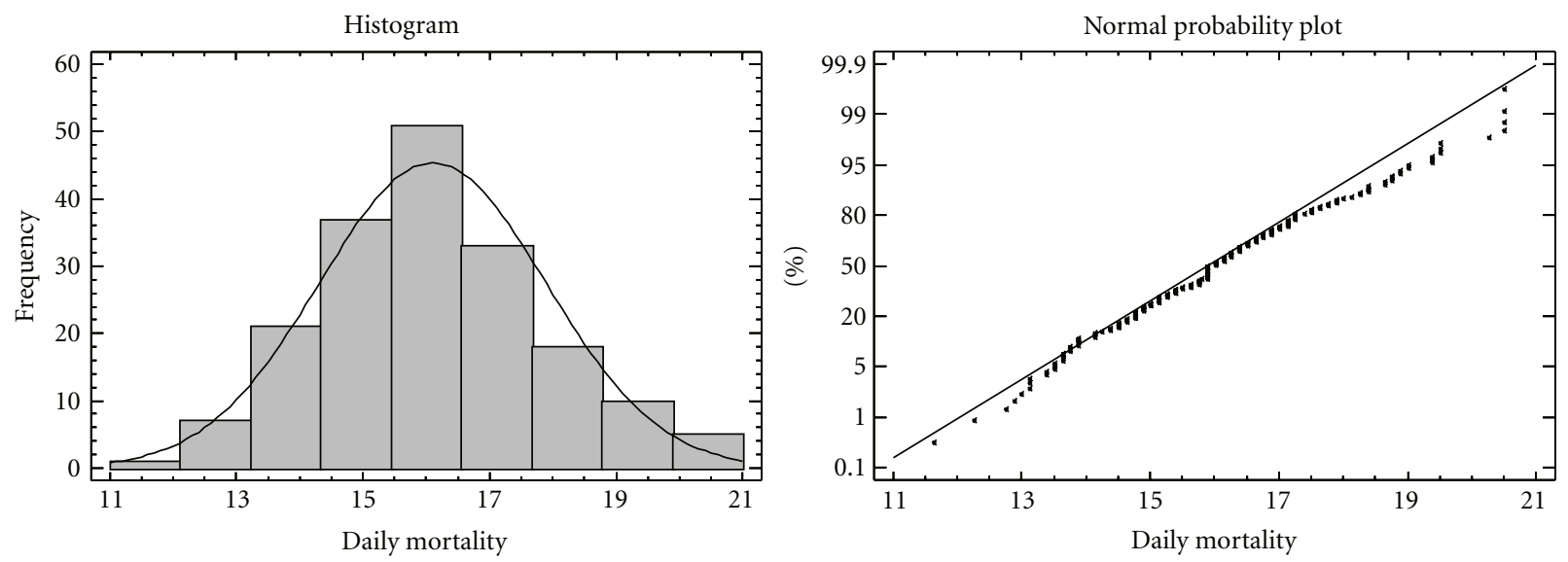

FIGURE 1: Normal distribution fitting of daily mortality in Chisinau in warm period, 2000-2008.

initial information given that air temperature is registered with $0.1^{\circ} \mathrm{C}$ resolution.

Statistical computations were performed, using the StatGraphics Centurion Data Analysis and Statistical Software [24].

\section{Results and Discussion}

3.1. Summary Statistics of Mortality. The average minimum mortality (about 15 deaths a day) was observed in July, the warmest month in Chisinau, and the maximum (about 18 deaths a day) in April (Table 2). Thus, the range of monthly averages is only 3 deaths; the range of their year-to-year variation is nearly double, at 6-7 deaths. Coefficient of correlation $(\mathrm{CV})$, derived as the percentage ratio of standard deviation (Sd) to the average value, is $9-10 \%$. Standardized skewness and kurtosis values within the range of -2 to +2 suggest that monthly deaths are close to being normally distributed. Across the warm season as a whole, daily death totals also follow a normal distribution (Figure 1).

Figure 2 demonstrates two outputs of ANOVA. In our case, mean mortality in April is statistically different from all other months; May is different from all months except June, and July is different from all months except August. All other combinations of monthly deaths show no significant differences between them. Both plots demonstrate clearly a seasonal course in mortality.
3.2. Comparison of the Information Content of Different Temperature Parameters. Undoubtedly, the quantification of temperature-mortality relationships requires the selection of an optimal metric. We found [30] that all daily temperature variables $\left(T_{\text {mean }}, T_{\text {max }}\right.$, and $\left.T_{\text {min }}\right)$ and corresponding apparent temperatures $\left(\mathrm{AT}_{\text {mean }}, \mathrm{AT}_{\text {max }}, \mathrm{AT}_{\text {min }}\right)$ are highly $(r>.95)$ and statistically significantly $(P<.001)$ correlated. Slightly weaker correlations, though still generally statistically significant, are observed between daily ranges of air and apparent temperature. However, the correlations between observed temperature values and daily ranges are weak $(r<0.3-0.4)$.

Principal component analysis [24] yields similar results (Table 3). From eight components, only the first two with eigenvalues $>1.0$ can be used; together they account for $98.2 \%$ of the variability in the original data set. Weights of components show that the first one, accounting for $76.6 \%$ of general variability, is formed by direct characteristics of air temperature and apparent temperature, the second component with weight $21.6 \%$ by their diurnal ranges. The practically equal information adequacy of direct temperature variables, demonstrated by component weights, assumes $a$ priori their adequacy in mortality description. This assumption is further supported by our research and is in full accord with the conclusion of Barnett et al. [31].

3.3. Identification of Mean Mortality Temperature. Figure 3(a) demonstrates the scatterplot of daily mortality 

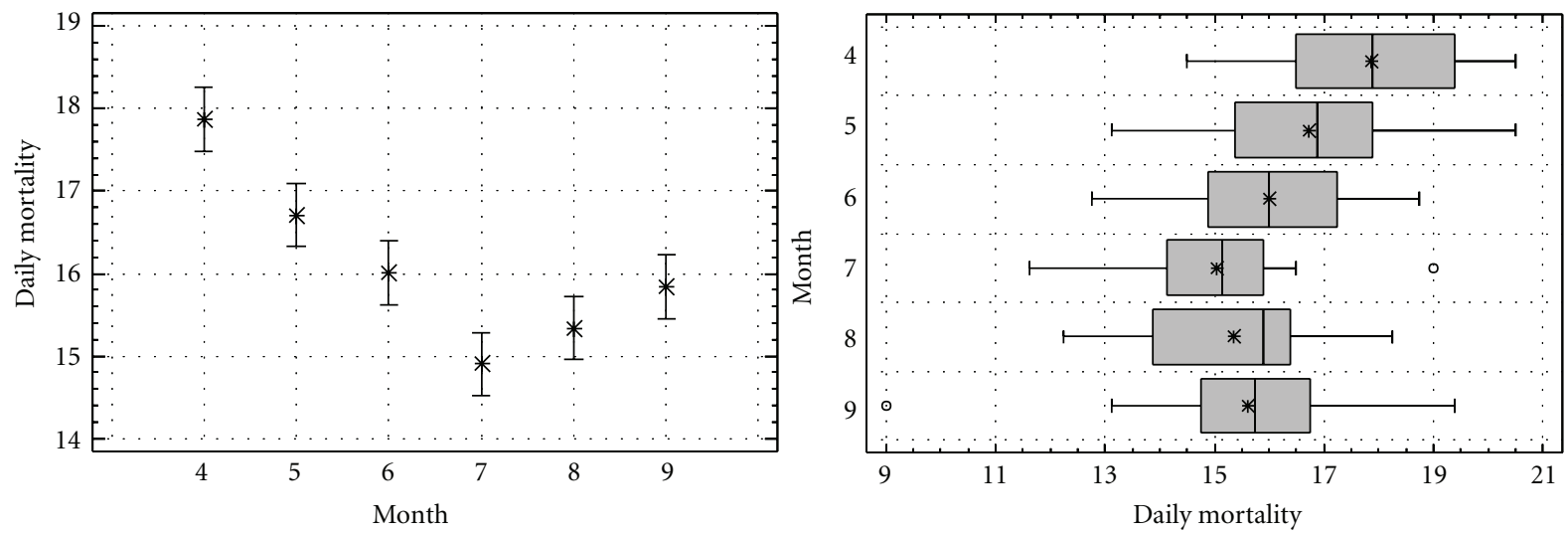

Figure 2: Mean (left) and Box-and-Whisker (right) Plots of daily deaths in warm period in Chisinau. (Means plot shows monthly death averages and Fisher's Least Significance Differences intervals. The overlapping of intervals signifies that two means are the same with $95 \%$ confidence.) (The Box-and-Whisker Plot divides data into four equal areas of frequency. The central boxes cover the middle $50 \%$ of the mortality, the box's sides are lower and upper $25 \%$ quartiles, the vertical line-the median, and the whiskers-the range. The means and outliers are marked as a single point $(*$ and $\circ$, resp.)).
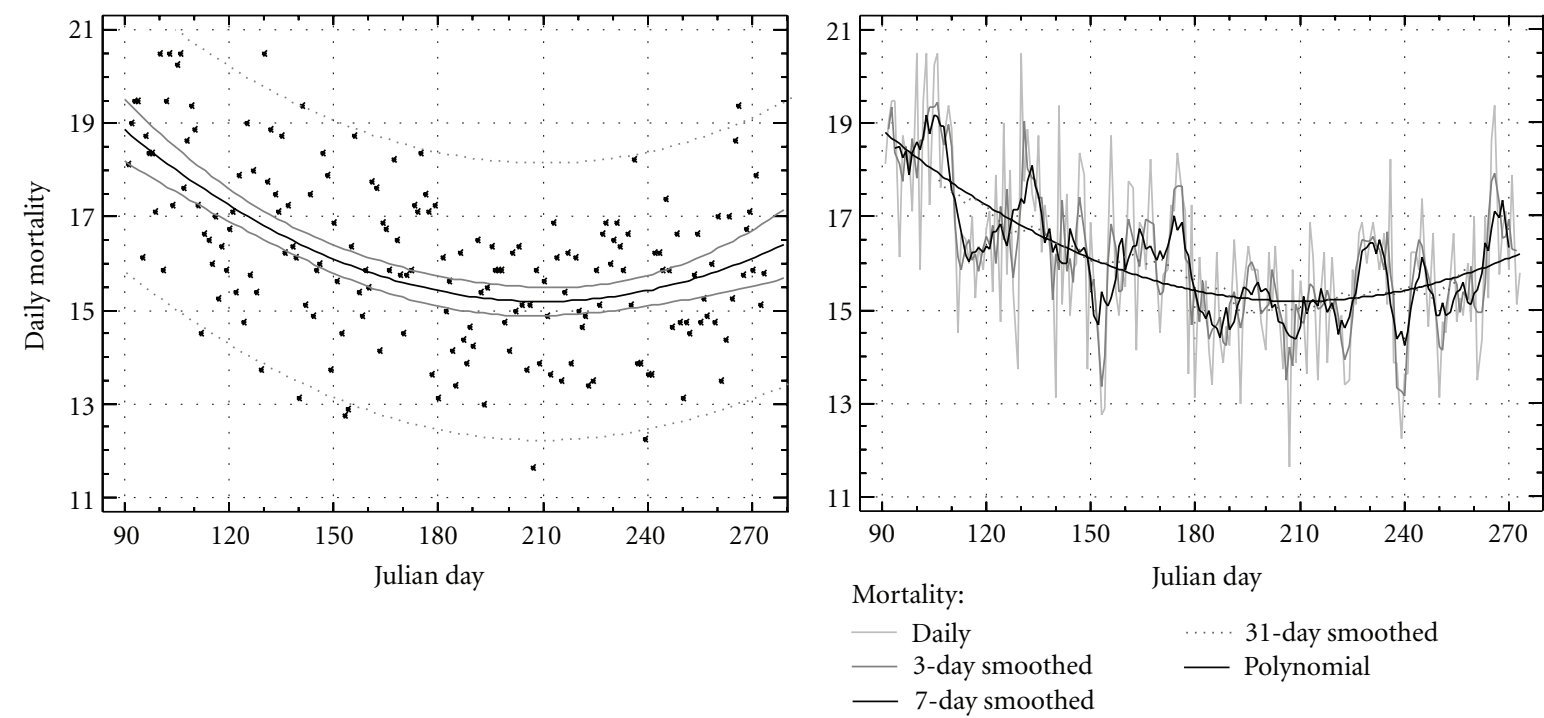

(a)

(b)

FIGURE 3: Scatter plot of warm period daily mortality in Chisinau (2000-2008), approximated by 2nd-order polynomial (a) and simple moving averages of different length (b).

TABle 3: Principal components analysis of the set of temperature characteristics: description of components (left) and components weights (right).

\begin{tabular}{|c|c|c|c|c|c|c|}
\hline \multirow{2}{*}{ Component number } & \multirow{2}{*}{ Eigenvalue } & \multicolumn{2}{|c|}{ Percentage } & \multirow{2}{*}{ Parameter } & \multicolumn{2}{|c|}{ Component weight } \\
\hline & & Of variance & Cumulative & & Component 1 & Component 2 \\
\hline 1 & 6.130 & 76.62 & 76.62 & $T_{\text {mean }}$ & 0.402 & -0.060 \\
\hline 2 & 1.725 & 21.56 & 98.18 & $T_{\max }$ & 0.403 & 0.020 \\
\hline 3 & 0.130 & 1.632 & 98.81 & $T_{\min }$ & 0.392 & -0.172 \\
\hline 4 & 0.012 & 0.149 & 99.96 & $\mathrm{AT}_{\text {mean }}$ & 0.401 & -0.091 \\
\hline 5 & 0.002 & 0.029 & 99.99 & $\mathrm{AT}_{\max }$ & 0.403 & -0.026 \\
\hline 6 & 0.001 & 0.009 & 100.0 & $\mathrm{AT}_{\min }$ & 0.388 & -0.205 \\
\hline 7 & 0.000 & 0.000 & 100.0 & $T_{\text {range }}$ & 0.165 & 0.668 \\
\hline 8 & 0.000 & 0.000 & 100.0 & $\mathrm{AT}_{\text {range }}$ & 0.146 & 0.685 \\
\hline
\end{tabular}




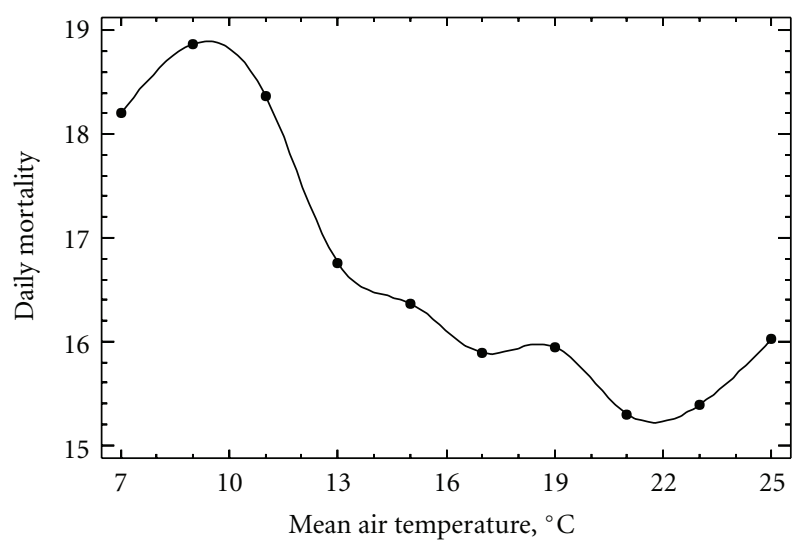

FIGURE 4: The third-order spline of daily mortality grouped by $2^{\circ} \mathrm{C}$ class intervals of mean daily temperature.

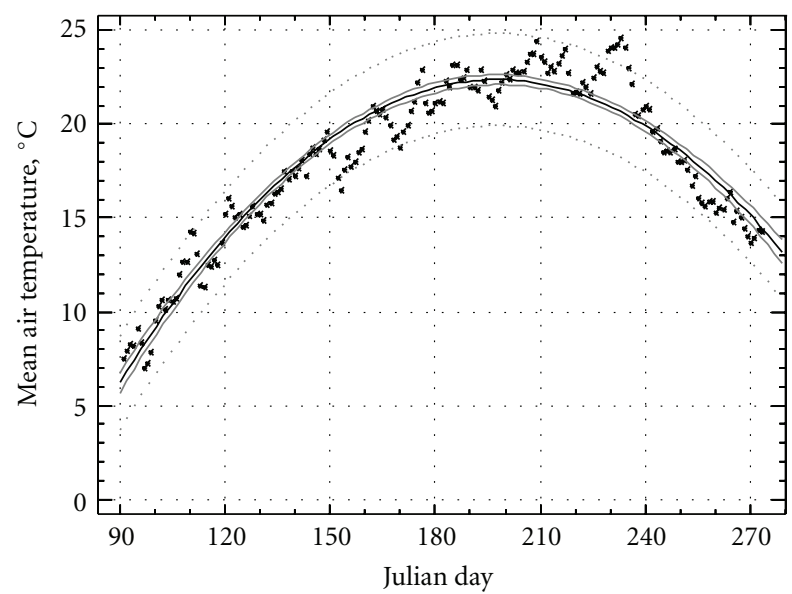

FIgURE 5: Plot of the dependence of mean air temperature on Julian day in Chisinau.

averaged for the whole period. The seasonality in data is evident and well approximated by the 2nd-order polynomial described by the equation:

$$
\begin{gathered}
\mathrm{Md}=26.47-0.108 * \text { Day }+0.00026 * \mathrm{Day}^{2}, \\
R^{2}=.3072, \quad P \leq .001,
\end{gathered}
$$

where Md is daily total deaths and Day is day of the beginning of year (Julian day).

The polynomial curve can be considered as a hypothetical seasonal course of daily mortality with an unlimited extension of the period of observations as well as with a reasonable extension of the period of smoothing. This assumption is well demonstrated in Figure 3(b) where daily mortality is smoothed by simple moving averages of different length. As the window in which the data are averaged increases from one to 31 days, the corresponding plots approach the polynomial approximation.

We can also note that in the warm period, starting from April 1, each subsequent day the total mortality is decreasing up to a certain moment (around 210 Julian Day, Figure 3), which could be treated as a thermal optimum or MMT, that is, the day (period) with temperature at which mortality is at a minimum. Thus, in Chisinau, using the polynomial approximation (Figure 3), the mean daily mortality (about 15.2 deaths) is observed in the late July-early August period when mean temperature reaches about $22^{\circ} \mathrm{C}$. An alternative approach-the 3rd-order spline of death counts in $2^{\circ} \mathrm{C}$ temperature intervals (Figure 4)-shows a MMT of $21.8^{\circ} \mathrm{C}$, with a mean mortality of 15.2 deaths as well.

3.4. Dependence of Daily Mortality on Mean Temperature. Over the summer, the mean air temperature is also very well approximated by a parabolic curve (Figure 5) that can be described by the equation:

$$
\begin{gathered}
T_{\text {mean }}=32.06+0.55 * \text { Day }-0.0014 * \mathrm{Day}^{2}, \\
R^{2}=.9204, \quad P \leq .001,
\end{gathered}
$$

where $T_{\text {mean }}$ is daily mean temperature and Day is Julian Day.

The comparison of two curves (Figures 3(a) and 5) presupposes the complex, mainly inverse relationship between mortality and temperature. We can also presuppose unacceptability of estimating this relationship as uniform for the entire temperature range because such an approach ignores the differences in mortality responses to temperature increase at two slopes of the dependency curve: below and above the thermal optimum (Figure 4). A linear regression analysis of daily mortality on $T_{\text {mean }}$ (Figure 6) shows that cold (descending) and heat (ascending) parts of the mortality curve need to be analyzed separately.

Table 4 demonstrates results of the regression analysis of relationships between daily mortality and $T_{\text {mean }}$ below the thermal optimum. All regression models, regardless of the level of smoothing, demonstrate very similar regression parameters, showing that prognostic power of the models is low sensitive to the length of moving average. At the same time, the 7-day smoothing was selected as optimal in comparison with three other alternatives as it is associated with high correlation and small errors yet still includes the entire weekly cycle of mortality. The 31-day averaging should be rejected as an evident "oversmoothing".

Thus, in Chisinau the dependency of daily mortality $(\mathrm{Md})$ on warm period's temperatures below MMT $\left(\mathrm{Md}_{<\mathrm{MMT}}\right)$ is well described by the following equation (notations as in Table 4):

$$
\begin{array}{cl}
\mathrm{Md}_{<\mathrm{MMT}} & =20.17-0.226 * T_{\text {mean }}, \\
r=.719, \quad & P \leq 0.001, \quad \mathrm{SE}=0.80, \\
& \mathrm{MA}=0.66 .
\end{array}
$$

The regression models estimate per se the mean response of mortality to ambient temperature change. In particular, the regression coefficients express human sensitivity to temperature exposure. So, proceeding from the regression coefficient $(-0.226)$ in (4), we can state at the $99 \%$ confidence level that in spring-early summer period the increase of ambient temperature up to its optimal value, for example by $4^{\circ} \mathrm{C}$, 


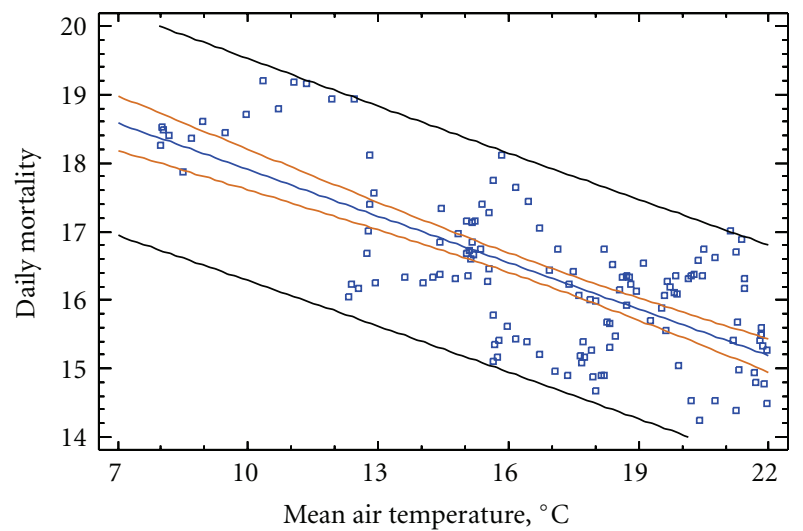

(a)

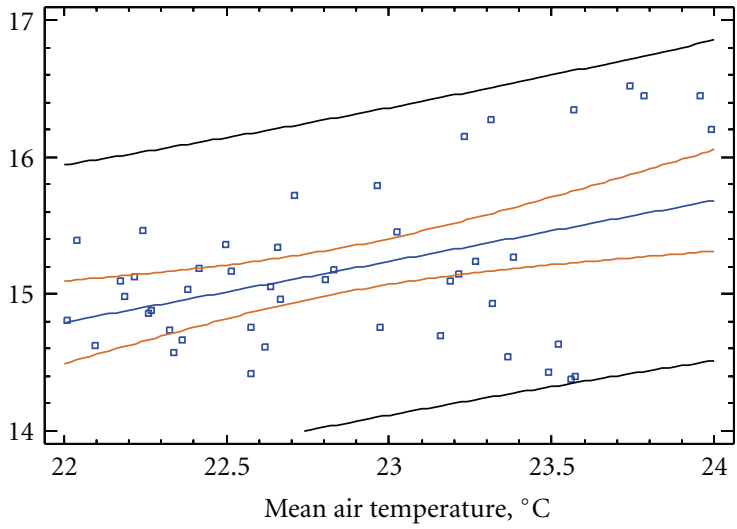

(b)

FIGURE 6: Dependencies of daily mortality (death cases) on air temperatures below (a) and above (b) thermal optimum. Both variables are smoothed by 7-day moving averages.

TABLE 4: Summary of simple regression analyses of daily mortality on mean air temperature below the thermal optimum for different lengths of smoothing.

\begin{tabular}{|c|c|c|c|c|c|c|c|}
\hline \multirow{2}{*}{$\begin{array}{l}\text { Period of } \\
\text { smoothing, days }\end{array}$} & \multicolumn{7}{|c|}{ Parameters of regressions } \\
\hline & Constant & Regression coefficients & $r$ & $r^{2}, \%$ & $P$ & Standard error, SE & Mean abs error, MA \\
\hline $\mathbf{0}$ & 20.29 & -0.237 & -0.742 & 55.00 & $>0.001$ & 0.80 & 0.65 \\
\hline 3 & 20.30 & -0.237 & -0.740 & 54.71 & $>0.001$ & 0.80 & 0.65 \\
\hline 7 & 20.17 & -0.226 & -0.719 & 51.63 & $>0.001$ & 0.80 & 0.66 \\
\hline 31 & 19.70 & -0.200 & -0.600 & 36.05 & $>0.001$ & 0.79 & 0.67 \\
\hline
\end{tabular}

TABLE 5: Simple linear regression models of 7-day moving averages of daily mortality on analogously smoothed daily air temperatures.

\begin{tabular}{|c|c|c|c|c|c|c|c|}
\hline \multirow{2}{*}{ Air temperature range } & \multicolumn{7}{|c|}{ Parameters of regressions } \\
\hline & Constant & Regression coefficient & $r$ & $r^{2}, \%$ & $P$ & Standard error & Mean abs error \\
\hline \multicolumn{8}{|c|}{ Mean temperature } \\
\hline$<\mathrm{MMT}$ & 20.17 & -0.226 & -0.719 & 51.63 & $>0.001$ & 0.80 & 0.66 \\
\hline$\geq \mathrm{MMT}$ & 4.987 & 0.446 & 0.419 & 17.54 & 0.004 & 0.55 & 0.43 \\
\hline \multicolumn{8}{|c|}{ Maximum temperature } \\
\hline$<\mathrm{MMT}$ & 21.18 & -0.218 & -0.725 & 52.7 & $>0.001$ & 0.80 & 0.65 \\
\hline$\geq \mathrm{MMT}$ & -1.05 & 0.568 & 0.466 & 21.7 & 0.028 & 0.57 & 0.46 \\
\hline \multicolumn{8}{|c|}{ Minimum temperature } \\
\hline$<\mathrm{MMT}$ & 19.34 & -0.244 & -0.717 & 51.5 & $>0.001$ & 0.81 & 0.67 \\
\hline$\geq \mathrm{MMT}$ & 11.80 & 0.189 & 0.174 & 3.04 & 0.216 & 0.57 & 0.45 \\
\hline
\end{tabular}

TABLE 6: Simple linear regression models of 7-day moving averages of daily mortality on analogously smoothed daily apparent temperatures.

\begin{tabular}{|c|c|c|c|c|c|c|c|}
\hline \multirow{2}{*}{ Air temperature range } & \multicolumn{7}{|c|}{ Parameters of regressions } \\
\hline & Constant & Regression coefficient & $r$ & $r^{2}, \%$ & $P$ & Standard error & Mean abs error \\
\hline \multicolumn{8}{|c|}{ Mean apparent temperature } \\
\hline$<\mathrm{MMT}$ & 19.36 & -0.195 & -0.699 & 48.91 & $>0.001$ & 0.83 & 0.68 \\
\hline$\geq \mathrm{MMT}$ & 14.96 & 0.010 & 0.014 & 0.020 & 0.920 & 0.58 & 0.44 \\
\hline \multicolumn{8}{|c|}{ Maximum apparent temperature } \\
\hline$<\mathrm{MMT}$ & 20.25 & -0.191 & -0.713 & 50.96 & $>0.001$ & 0.82 & 0.67 \\
\hline$\geq \mathrm{MMT}$ & 10.99 & 0.150 & 0.198 & 3.92 & 0.187 & 0.59 & 0.46 \\
\hline \multicolumn{8}{|c|}{ Minimum apparent temperature } \\
\hline$<\mathrm{MMT}$ & 18.50 & -0.206 & -0.690 & 47.58 & $>0.001$ & 0.84 & 0.70 \\
\hline$\geq \mathrm{MMT}$ & 15.66 & -0.027 & -0.041 & 0.17 & 0.768 & 0.56 & 0.44 \\
\hline
\end{tabular}


causes a decrease in daily mortality by one death. This also means that for average daily mortality in the observed period (16.1 deaths) a $1^{\circ} \mathrm{C}$ change in mean daily temperature causes $1.4 \%$ decrease in total death cases.

A somewhat different picture takes place on the ascending slope of temperature-mortality relationship after air temperatures have crossed MMT. Here, the analogous regression of daily mortality on mean temperature $\left(\mathrm{Md}_{\geq \mathrm{MMT}}\right)$ is well described by the equation:

$$
\begin{gathered}
\mathrm{Md}_{\geq \mathrm{MMT}}=4.99+0.446 * T_{\text {mean }}, \\
r=.419, \quad P \leq .01, \quad \mathrm{SE}=0.55, \\
\mathrm{MA}=0.43 .
\end{gathered}
$$

In other words, a mean temperature increase above thermal optimum leads to the corresponding increase of daily mortality (about 0.5 deaths per $1^{\circ} \mathrm{C}$ ) that is practically twice more than its initial decrease caused by seasonal warming. Transformation of this value in relative daily mortality shows that high mean temperatures (those above MMT) cause on the average about $2.8 \%$ increase of daily mortality. This figure is in the range of European estimations-between $0.7 \%$ and $3.6 \%$ [32]. In Chisinau's "normal warm season" the range of these temperatures, smoothed in weekly windows (Figure 6), is only two degrees (from $22^{\circ} \mathrm{C}$ to $24^{\circ} \mathrm{C}$ ). Because of the lower range of temperatures and smaller sample size, there is less certainty in the slope of the ascending limb of the regression line in comparison with that for the descending one ((5) versus (4)).

The effects of higher temperatures, describable as heat days, are considered in a special paper [29].

\subsection{Maximum and Minimum Temperature as Predictors of} Mortality. The splines of daily mortality, grouped by $2^{\circ} \mathrm{C}$ class intervals of maximum and minimum temperatures, showed their optimal values around $28^{\circ} \mathrm{C}$ and $18^{\circ} \mathrm{C}$, respectively. These values, received as corresponding temperatures on the day of minimum mortality, were similar, $27.6^{\circ} \mathrm{C}$ and $17.4^{\circ} \mathrm{C}$.

The parameters of regression models of daily mortality on increasing $T_{\max }$ and $T_{\min }$ are shown in Table 5 where, for easy comparison, the regressions' parameters for $T_{\text {mean }}$ are repeated. Obviously, both variables are good predictors of a temperature-conditioned change in daily mortality for temperatures below MMT. Again, based on the warm season average daily deaths in Chisinau and regression coefficients, it can be stated that each $1^{\circ} \mathrm{C}$ increase of $T_{\max }$ and $T_{\min }$ up to the thermal optima causes respectively $1.3-1.4 \%$ and $\sim 1.5 \%$ decreases in daily mortality. Thus, in the observed temperature range, mortality is slightly more sensitive to minimal night temperatures, while the sensitivity to mean and maximum daily temperatures is practically the same.

The increase of maximum temperatures above their optimum value causes an expected heightened mortality. Under such weather conditions, each additional $1^{\circ} \mathrm{C}$ of $T_{\max }$ yields a $2.9 \%$ increase of daily deaths-again about twice more that the positive effect of tolerable heat. The effect of minimum temperatures is not statistically significant.
3.6. Apparent Temperature versus Air Temperature in an Analysis of Mortality Sensitivity. The values of $\mathrm{AT}_{\text {mean }}, \mathrm{AT}_{\max }$, and $\mathrm{AT}_{\text {min }}$ corresponding to minimal mortality, identified concurrently through a narrow-bands and long-term apparent temperature-mortality relationships, were respectively $21.5^{\circ} \mathrm{C}\left(21.9^{\circ} \mathrm{C}\right), 27.8^{\circ} \mathrm{C}\left(26.8^{\circ} \mathrm{C}\right)$, and $15.6^{\circ} \mathrm{C}\left(16.6^{\circ} \mathrm{C}\right)$. Given the strong correlation between air temperature and apparent temperature, their relationships with mortality below MMTs are rather similar, with slightly weaker correlation for the latter (Table 6). For all AT above MMT, no statistically significant relationships between their increase and daily mortality were found.

A somewhat weaker relationship between mortality and apparent temperature, in part explained by the relatively low humidity of the Moldavian warm season, emphasizes the necessity of direct accounting for humidity in assessing the weather-health relationships.

\section{Conclusions}

The statistical analysis of temperature-mortality relationships in Chisinau (Moldova) in the warm period suggests the following principal conclusions.

(1) An initial increase of ambient temperature from spring to summer months occurs with a decrease in human mortality, with its minimal mean values observed in July (14.9 \pm 0.27 deaths per day). A transition from daily mortality decrease to its increase as the season progresses is observed in late Julyearly August. The second-order polynomial is a good describer both of the seasonal course of mortality and of its minimal value.

(2) The linear regression analysis is a good "estimator" of daily mortality dependence on air temperature in the warm season, but these dependencies must be estimated independently for descending and ascending parts of the mortality-temperature curve. A narrowband approach, based on the distribution of daily mortality in $2^{\circ} \mathrm{C}$ temperature intervals is a good identifier of the minimum mortality temperature.

(3) In a warm period, due to high multicolinearity, the prognostic power of mean, maximum, and minimum temperatures is adequate. Inclusion of air humidity in the analysis (through an apparent temperature) has not resulted in the strengthening of regression models and in this case performed worse than temperature variables alone.

(4) The analysis of historical dependence of daily mortality on air temperature is a reliable tool for epidemiological studies and develops a good baseline for heat impacts early warning. At the same time, such analysis is insufficient to solve this task in full because it "hides" individual heat events, and an additional heat-episode analysis is needed.

(5) Also, the identified relationships between ambient temperatures and human mortality may not be stationary in time, being only relevant to the time 
period studied (2000-2008). There are good reasons to expect that the equations derived in this work may change over time, both as a function of societal/technological changes as well as of climate change. Undoubtedly, with further accumulation of reliable daily meteorological and medical information, such research should be continued.

\section{Acknowledgment}

The research described in this paper was made possible in part by Award no. MOB-2928-CS-08 of the U.S. Civilian Research and Development Foundation for the Independent States of the Former Soviet Union (CRDF).Any opinions, finding and conclusions, or recommendations expressed in this material are those of the authors and do not necessary reflect those of the CRDF.

\section{References}

[1] R. Basu, W. Y. Feng, and B. D. Ostro, "Characterizing temperature and mortality in nine California counties," Epidemiology, vol. 19, no. 1, pp. 138-145, 2008.

[2] C. Carson, S. Hajat, B. Armstrong, and P. Wilkinson, "Declining vulnerability to temperature-related mortality in London over the 20th century," American Journal of Epidemiology, vol. 164, no. 1, pp. 77-84, 2006.

[3] U. Confalonieri, B. Menne, R. Akhtar et al., "Human health," in Climate Change 2007: Impacts, Adaptation and Vulnerability. Contribution of Working Group II To the Fourth Assessment Report of the Intergovernmental Panel on Climate Change, M. L. Parry, O. F. Canziani, P. J. Palutikof, P. van der Linden, and C. E. Hanson, Eds., pp. 391-431, Cambridge University Press, Cambridge, UK, 2007.

[4] S. N. Gosling, J. A. Lowe, G. R. McGregor, M. Pelling, and B. D. Malamud, "Associations between elevated atmospheric temperature and human mortality: a critical review of the literature," Climatic Change, vol. 92, no. 3-4, pp. 299-341, 2009.

[5] S. N. Gosling, G. R. McGregor, and J. A. Lowe, "Climate change and heat-related mortality in six cities Part 2: climate model evaluation and projected impacts from changes in the mean and variability of temperature with climate change," International Journal of Biometeorology, vol. 53, no. 1, pp. 31-51, 2009.

[6] S. N. Gosling, G. R. McGregor, and A. Páldy, "Climate change and heat-related mortality in six cities. Part 1: model construction and validation," International Journal of Biometeorology, vol. 51, pp. 525-540, 2007.

[7] G. Jendritzky and R. de Dear, "Adaptation to thermal environment," in Biometeorology for Adaptation to Climate Variability and Change, K. L. Ebi, J. Burton, and G. R. McGregor, Eds., pp. 9-32, Springer, 2009.

[8] M. Laaidi, K. Laaidi, and J. P. Besancenot, "Temperaturerelated mortality in France, a comparison between regions with different climates from the perspective of global warming," International Journal of Biometeorology, vol. 51, no. 2, pp. 145153, 2006.

[9] F. Matthies, G. Bickler, N. C. Marin, and S. Hales, Heat-Health Action Plans: Guidance, WHO Regional Office for Europe, Copenhagen, Denmark, 2008.
[10] B. Menne, F. Apfel, S. Kovats, and F. Racioppi, Eds., Protecting Health in Europe From Climate Change, WHO Regional Office for Europe, 2008.

[11] C. Schär, P. L. Vidale, D. Lúthi et al., "The role of increasing temperature variability in European summer heatwaves," Nature, vol. 427, no. 22, pp. 332-336, 2004.

[12] M. Beniston, "The 2003 heat wave in Europe: a shape of things to come? An analysis based on Swiss climatological data and model simulations," Geophysical Research Letters, vol. 31, Article ID L02202, 4 pages, 2004.

[13] B. Armstrong, "Models for the relationship between ambient temperature and daily mortality," Epidemiology, vol. 17, no. 6, pp. 624-631, 2006.

[14] R. Basu, "High ambient temperature and mortality: a review of epidemiologic studies from 2001 to 2008," Environmental Health, vol. 8, article 40, 2009.

[15] R. Basu, F. Dominici, and J. M. Samet, "Temperature and mortality among the elderly in the United States: a comparison of epidemiologic methods," Epidemiology, vol. 16, no. 1, pp. 5866, 2005.

[16] S. Hajat, R. S. Kovats, R. W. Atkinson, and A. Haines, "Impact of hot temperatures on death in London: a time series approach," Journal of Epidemiology and Community Health, vol. 56, no. 5, pp. 367-372, 2002.

[17] J. Kyselý and J. Kim, "Mortality during heat waves in South Korea, 1991 to 2005: how exceptional was the 1994 heat wave?" Climate Research, vol. 38, no. 2, pp. 105-116, 2009.

[18] J. Kyselý and B. Kř́íž, "Decreased impacts of the 2003 heat waves on mortality in theCzech Republic: an improved response?" International Journal of Biometeorology, vol. 52, pp. 733-745, 2008.

[19] P. Michelozzi, F. de Donato, L. Bisanti et al., "The impact of the summer 2003 heat waves on mortality in four Italian cities," Euro Surveillance, vol. 10, no. 7, pp. 161-165, 2005.

[20] R. Corobov, S. Sheridan, A. Overcenco, and N. Terinte, "Air temperature trends and extremes in Chisinau (Moldova) as evidence of climate change," Climate Research, vol. 42, no. 3, pp. 247-256, 2010.

[21] R. G. Steadman, "A universal scale of apparent temperature," Journal of Climate \& Applied Meteorology, vol. 23, no. 12, pp. 1674-1687, 1984.

[22] S. Hajat, B. Armstrong, M. Baccini et al., "Impact of high temperatures on mortality: is there an added heat wave effect?" Epidemiology, vol. 17, no. 6, pp. 632-638, 2006.

[23] M. Pascal, K. Laaidi, M. Ledrans et al., "France's heat health watch warning system," International Journal of Biometeorology, vol. 50, no. 3, pp. 144-153, 2006.

[24] Statgraphics Centurion XVI User Manual, StatPoint Technologies, 2010, http://www.statgraphics.com.

[25] V. M. Muggeo, "A note on temperature effect estimate in mortality time series analysis," International Journal of Epidemiology, vol. 33, pp. 1151-1153, 2004.

[26] M. A. Vigotti, V. M. R. Muggeo, and R. Cusimano, "The effect of birthplace on heat tolerance and mortality in Milan, Italy, 19801989," International Journal of Biometeorology, vol. 50, no. 6, pp. 335-341, 2006.

[27] W. R. Keatinge, G. C. Donaldson, E. Cordioli et al., "Heat related mortality in warm and cold regions of Europe: observational study," British Medical Journal, vol. 321, pp. 670-673, 2000.

[28] G. C. Donaldson, W. R. Keatinge, and S. Näyhä, "Changes in summer temperature and heat-related mortality since 1971 
in North Carolina, South Finland, and Southeast England," Environmental Research, vol. 91, no. 1, pp. 1-7, 2003.

[29] R. Corobov, S. Sheridan, K. Ebi, and N. Opopol, "Heat-related mortality in Moldova: the summer of 2007," International Journal of Climatology, 2012.

[30] R. Corobov and N. Opopol, "Some temperature-mortality relationships in the warm season in Chisinau," Curier Medical, vol. 2, pp. 35-43, 2010.

[31] A. G. Barnett, S. Tong, and A. C. A. Clements, "What measure of temperature is the best predictor of mortality?" Environmental Research, vol. 110, no. 6, pp. 604-611, 2010.

[32] WHO, Improving Public Health Responses to Extreme Weather/Heat-Waves-EuroHEAT Technical Summary, WHO Regional Office for Europe, Copenhagen, Denmark, 2009. 

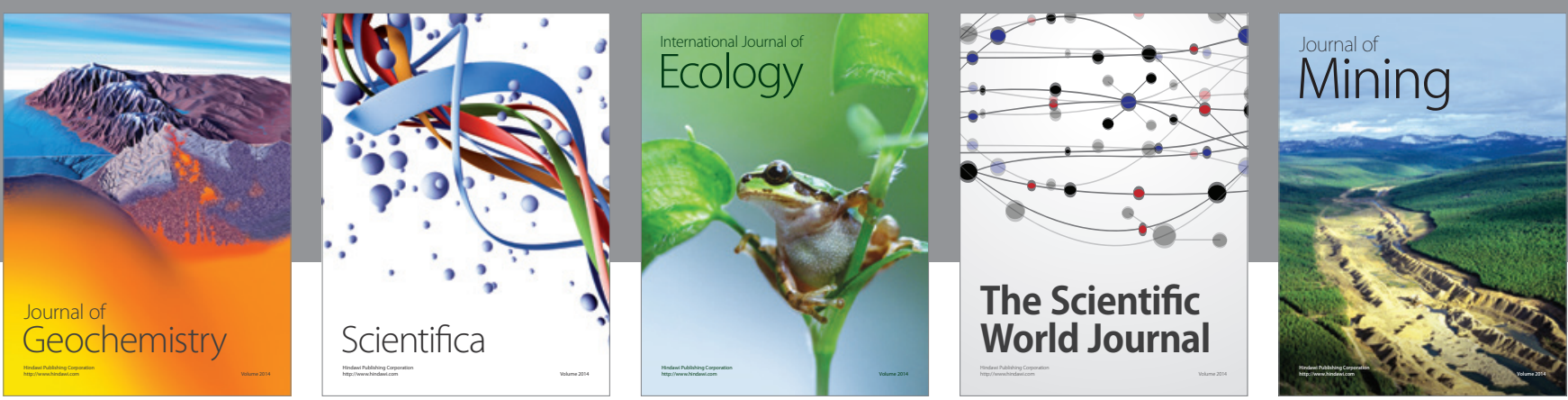

The Scientific World Journal
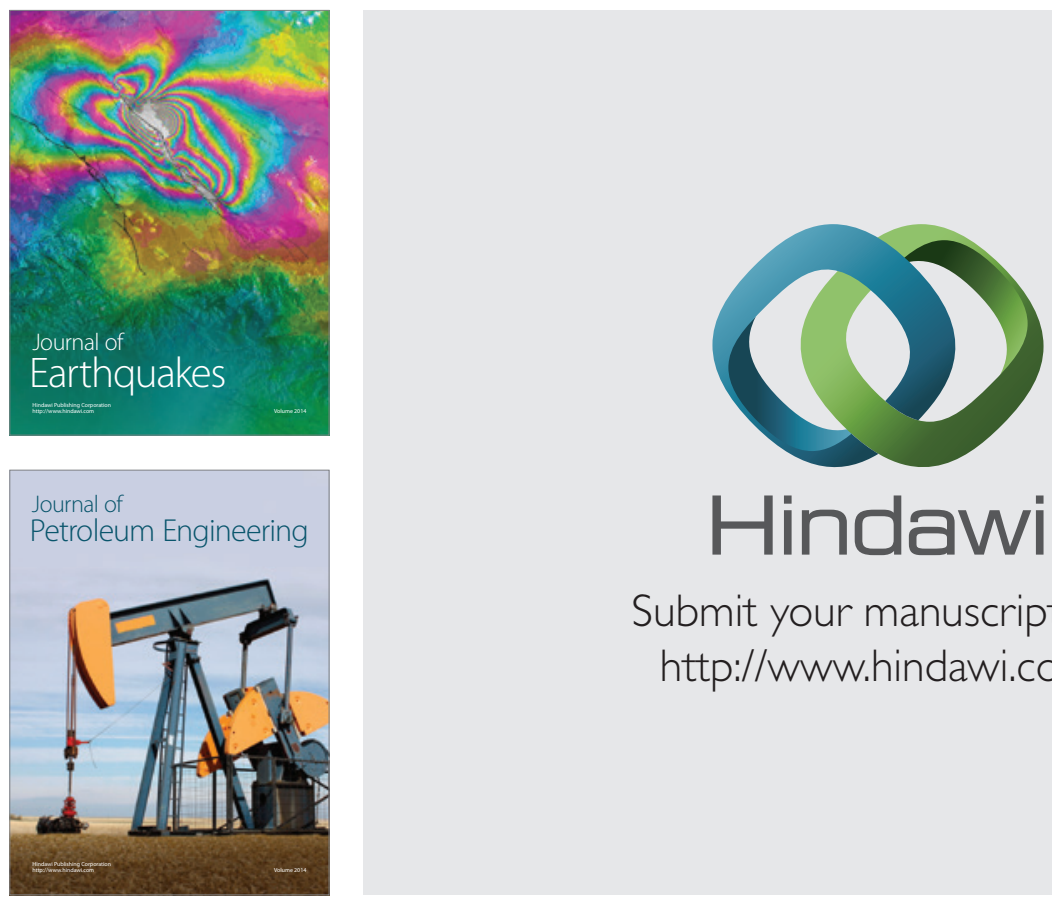

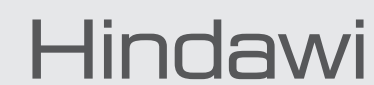

Submit your manuscripts at

http://www.hindawi.com
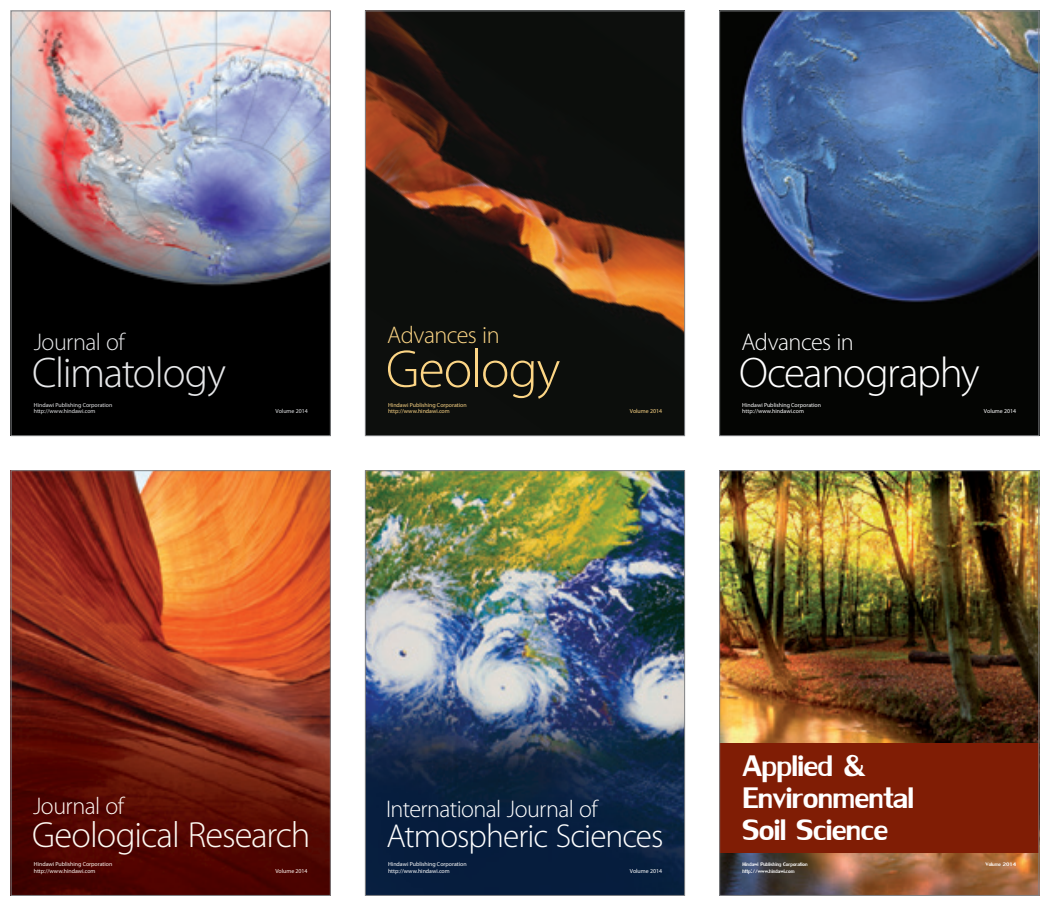
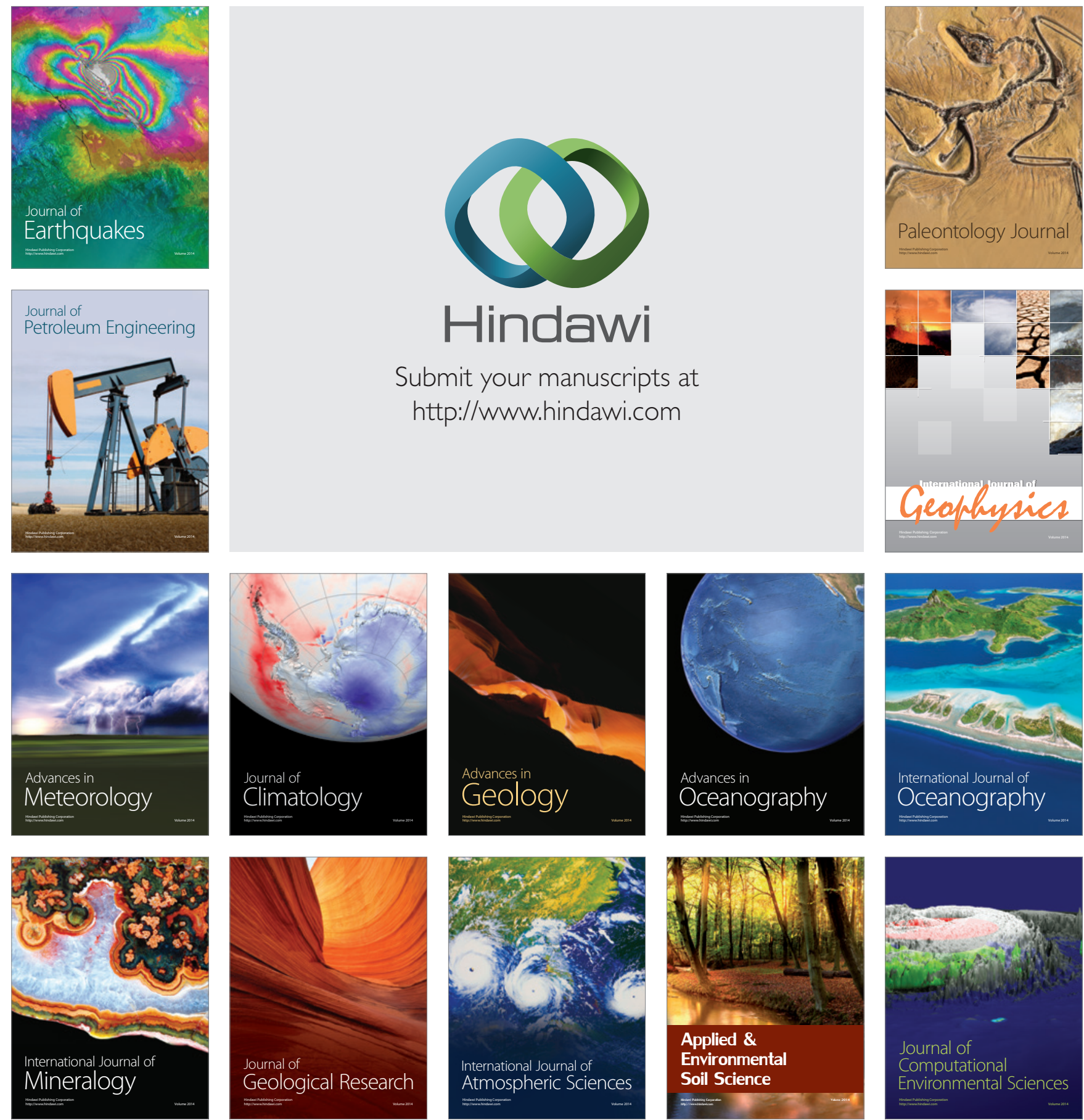